\title{
A Semi-deterministic Wear Model Considering the Effect of Zinc Dialkyl Dithiophosphate Tribofilm
}

\author{
Ali Ghanbarzadeh ${ }^{1} \cdot$ Pourya Parsaeian $^{1}$ - Ardian Morina ${ }^{1} \cdot$ Mark C. T. Wilson $^{1}$ • \\ Marcel C. P. van Eijk ${ }^{2}$ - Ileana Nedelcu ${ }^{2}$ Duncan Dowson ${ }^{1} \cdot$ Anne Neville $^{1}$
}

Received: 23 April 2015/ Accepted: 23 November 2015/Published online: 23 December 2015

(C) The Author(s) 2015. This article is published with open access at Springerlink.com

\begin{abstract}
Tribochemistry plays a very important role in the behaviour of systems in tribologically loaded contacts under boundary lubrication conditions. Previous works have mainly reported contact mechanics simulations for capturing the boundary lubrication regime, but the real mechanism in which tribofilms reduce wear is still unclear. In this paper, the wear prediction capabilities of a recently published mechanochemical simulation approach (Ghanbarzadeh et al. in Tribol Int, 2014) are tested. The wear model, which involves a time- and spatially dependent coefficient of wear, was tested for two additive concentrations and three temperatures at different times, and the predictions are validated against experimental results. The experiments were conducted using a mini-traction machine in a sliding/rolling condition, and the spacer layer interferometry method was used to measure the tribofilm thickness. Wear measurements have been taken using a white-light interferometry. Good agreement is seen between simulation and experiment in terms of tribofilm thickness and wear depth predictions.
\end{abstract}

Keywords Boundary lubrication · Tribochemistry · Contact mechanics . Wear

Ali Ghanbarzadeh

mnag@leeds.ac.uk; a.ghanbarzadeh@leeds.ac.uk

$\square$ Pourya Parsaeian

p.parsaeian@leeds.ac.uk

1 Institute of Functional Surfaces, School of Mechanical Engineering, University of Leeds, Leeds LS2 9JT, UK

2 SKF Engineering and Research Centre, Nieuwegein, The Netherlands

\section{Introduction}

Wear is defined as the material loss that occurs on the surface of contacting bodies in relative motion. Wear has a major impact on the reliability of tribosystems and determines the durability of machine elements. Understanding the true mechanisms of this phenomenon can help engineers design more efficient machine parts and also results in the better maintenance of those elements. Predicting wear is one of the most important challenges in the whole engineering field, and a lot of attempts have been made to predict the material loss on the contacting surfaces. Wear of surfaces mostly occurs when solid-solid contact happens between the surfaces and the load is carried by the asperities of the bodies.

One of the first attempts to model wear was made by Archard [2]. A wear model was introduced based on the load and rubbing distance of the contacting bodies. This model has been used in a wide range of wear studies, and the results show good agreements with experimental observations.

A model was developed for oxidational wear in boundary lubrication by Sullivan [3]. A mathematical model was developed in which wear was related to applied load and involves many other factors that together can be assumed as Archard's wear coefficient. Stolarski [4] developed a statistical model for wear prediction in boundary-lubricated contacts that could account for elastic and plastic contacts and also was capable of predicting the coverage of the tribofilm on contact asperities and thus predicting wear. That approach used the Greenwood and Williamson model of contact mechanics [5]. Zhang et al. [6] derived a model for micro-contacts, considering elastic, elastic-plastic and even fully plastic contacts and using a Jaeger equation to calculate the asperity flash temperature 
[7]. They used classical wear theories to calculate the probability of contact being covered by physically or chemically absorbed layers. Several modelling works used Archard's wear equation in contact mechanics simulations and predicted wear by applying Archard's law at local scales and modifying the geometries.

Bortoletto et al. [8] simulated a single ball-on-disc experiment by the finite element method and used Archard's wear equation to simulate wear. They validated the simulation results with experiments and showed good agreement. Oqvist [9] also used a finite element model to simulate a contact and implemented Archard's law to calculate wear using an updated geometry with different step sizes. Ilincic et al. [10, 11] used the boundary element method and also a combined boundary-finite element method to simulate wear in tribometers using a localized Archard's law. Sfantos et al. [12, 13] also developed boundary element simulations to calculate wear in sliding wear conditions.

Hegadekatte et al. [14] developed a multi-timescale model for wear prediction. They used commercial codes for determining their contact pressure and deformations and then used Archard's wear equation for calculating wear. Andersson et al. [15] used a wear model and implemented FFT-based contact mechanics simulations to calculate contact pressure and deformations. They simulated a ball-on-disc wear experiment and validated their simulation results with experiments. All these models use Archard's wear law to calculate wear at local scales without considering the tribofilm as an important mechanism in defining the wear behaviour of the system.

Antiwear additives are generally known to form protective tribofilms on the surface of contacting bodies. The most common such additive is zinc dialkyl dithiophosphate (ZDDP) [16], which can form tribofilms on various materials including steel, diamond-like carbon (DLC) and Si/Al alloys [17-27]. Though extensively studied, the specific processes involved in formation and removal of tribofilms in these different systems are not yet fully understood. In the case of inert surfaces such as DLCs, tribofilms do form, but some reports indicate that they can be easily removed from the surface $[25,28]$. The tribofilm has negligible effect on the wear [25], with wear resistance properties being dominated by those of the DLC itself, and with the type of DLC having an important influence [24]. In contrast, ZDDP tribofilms formed on steel surfaces have been shown to contain iron in the bulk [29], indicating a significant interaction between the ZDDP and the substrate. This can be due to several reasons: (1) chemical reaction resulting from cation exchange in the polyphosphate $\left(\mathrm{Fe}^{3+}\right.$ in place of $\mathrm{Zn}^{2+}$ ); (2) mechanical mixing in the process of high load and shear stress; and (3) digestion of the iron oxide abrasive particles in the bulk of the tribofilm. There are different wear reduction scenarios reported for ZDDP, but the most accepted one is coverage of the surface, prevention of direct asperity-asperity contact and increasing the load-carrying capacity of surfaces.

In recent work, Andersson et al. [30] used contact mechanics of rough surfaces considering the ZDDP tribofilm properties and also the tribofilm formation on asperities. They used an Arrhenius equation for the tribofilm formation and Archard's wear equation for wear predictions. The novelty of this work was considering the tribofilm and also film formation rate during the time. The film formation followed an exponential formulation based on an Arrhenius equation. The model was based on contact pressure and flash temperature, and these parameters were responsible for tribofilm growth. One of the drawbacks of that work was considering the same wear coefficient for the tribofilm and the substrate which over-estimates the wear of the system in the case where a tribofilm is separating contacting asperities. The main output of the work was the inhomogeneous tribofilm formed on the contacting spots of the rough surfaces, but no prediction of wear with respect to the formation of the tribofilm was reported in the work.

A model developed by Bosman et al. [31] proposed a numerical formulation for mild wear prediction under boundary lubrication conditions for ZDDP on steel surfaces. They suggested that ZDDP chemically reacted layers are the main mechanisms responsible for protecting boundary-lubricated systems, and when these layers are worn off, the system will restore the balance and the substrate will react with the oil to produce a tribofilm. The model for the formation of the tribofilm on the surface was based on a diffusion model. They also proposed a transition from mild to more severe wear by making a complete wear map [32]. Bosman et al. [31] suggested that the removal of the tribofilm is due to the plastic deformation of the film and the amount of wear is due to the chemical reaction that takes place to restore the chemical balance, which is much less than the amount of wear in direct interaction of asperities. They showed that the concentration of the substrate atoms across the depth of the tribofilm varies and the removal of the substrate atoms present in the tribofilm is the main reason for wear of boundary-lubricated systems in the presence of the tribofilm. This model is a good explanation of the effect of tribofilms on reducing the wear of the boundary-lubricated system.

Recently, Ghanbarzadeh et al. [1] developed a numerical framework that considers tribochemistry in the mechanistic modelling of boundary lubrication. The model shows the possibility of seeing the effect of tribofilms on the tribological behaviours of the system. In addition to modelling the tribofilm formation via the thermodynamics of interfaces and kinetics of tribochemical reactions, a wear model was included based on a modification of the Archard wear 
law to account for local tribofilm properties. The complete model was calibrated against published ball-on-ring experimental data, and then, brief illustrations were given of how the numerical framework can predict the evolution of surface roughness, tribofilm thickness, and the transition from running-into steady-state wear.

Although in Ref. [1] the tribofilm growth model was calibrated using tribofilm thickness data from the literature [43], there was no validation of wear or surface topography aspects of the model due to a lack of experimental data. In this paper, the model is adapted to a new set of experimental data in which wear measurements have been taken to test the wear prediction capability of the model. In essence, capturing the tribofilm behaviour is the first step of the numerical framework. Once the tribofilm behaviour is captured appropriately, its effect on the wear of the system is studied. The study focuses on the effect of ZDDP tribofilms on the reduction in wear on steel surfaces and will apply to any system that operates with the same mechanisms. The wear model and mechanism reported in this paper do not necessarily apply for all antiwear additives and surfaces. However, the assumptions made seem to be reasonable for the case of steel and ZDDP. The model is used to develop insights into the wear mechanism occurring in the presence of the tribofilm over the whole duration of a test, rather than just at steady state.

An outline of the model is given in Sect. 2, which includes some additional relevant details not presented in [1]. The experimental procedure and associated new data are described in Sect. 3, after which the numerical predictions are discussed and compared with experiments in Sect. 4. Conclusions are drawn in Sect. 5.

\section{Numerical Model}

The model applied here is that developed by Ghanbarzadeh et al. [1], which implemented tribofilm formation and removal into a deterministic contact mechanics simulation for contact of two rough surfaces in different configurations. The model contains the following major components:

(1) A deterministic contact code for rough surfaces using elastic-perfectly plastic theory;

(2) A semi-analytical tribofilm growth model based on thermodynamics of interfaces;

(3) Tribofilm mechanical properties;

(4) And a modification of Archard's wear law considering the effect of ZDDP tribofilm.

A flowchart indicating the whole numerical procedure is shown in Fig. 1. A brief description of the overall model is given below, with focus on the wear modelling aspects. Further details are available in Ref. [1].
The digitized rough surfaces needed for the deterministic simulations are generated using Gaussian random number distribution and digital filters the same as in the work reported by Tonder et al. [33]. The contact model is based on that of Tian and Bhushan [34], which considers the complementary potential energy and determines the contact pressures and surface deformations. An elasticperfectly plastic contact model based on Sahlin et al. [35] is then used, where it is assumed that the pressures above the hardness of materials are truncated out of the calculation. The asperities that experience pressures close to the hardness of the material will float freely, and the contact calculation is only carried out for elastically deformed ones. The contact pressures calculated from this method are realistic, but because of its shortcomings in considering the nonlinear behaviour of the materials, the plastic deformations might be underestimated. However, this method is well known in the literature. The detailed discussion on the plastic deformation model can be found in Ref. [35].

Tribofilm growth is taken to be a combination of tribofilm formation and removal at the same time. The formation of the tribofilm is assumed to be due to chemical reactions at the interface and follows the kinetics of tribochemical reactions, which are activated not only by temperature but also by mechanical rubbing [36-38]. Active collision theories used by Bulgarevich et al. [36, 37] to explain tribochemical reactions were adopted in the development of the tribofilm growth model used here. It has been suggested that tribofilm removal can be as important as tribofilm formation [40, 41], so the tribofilm formation model is augmented with a phenomenological term to account for concurrent removal of the tribofilms. The resulting model for the growth of tribofilm thickness $h$ is as follows:

$h=h_{\max }\left(1-e^{\left(-\frac{k_{1} T}{h^{\prime}} \cdot x_{\text {tribo }} \cdot t\right)}\right)-C_{3}\left(1-e^{-C_{4} t}\right)$

where $h_{\max }, k_{1}, k_{1}$ and $h^{\prime}$ are the maximum tribofilm thickness, Boltzmann and Plank's constants and $T$ is the temperature at which tribochemical reactions occur. The temperature used in this model is the temperature at asperities, which is the summation of flash temperature and bulk temperature [39]. The flash temperature is calculated using Blok's theory and the formulation that was reported by Kennedy et al. [42]. The term $x_{\text {tribo }}$ was introduced by Bulgarevich et al. [36, 37], to account for the effect of mechanical rubbing on the initiation of tribochemical reactions, and combined with the contact mechanics model mentioned above by Ghanbarzadeh et al. [1]. In principle, this term relates to the proportion of transition states in the tribochemical reaction that result from mechanical activation; in practice, it is a fitting parameter to be calibrated via experiments providing in situ measurements of tribofilm 


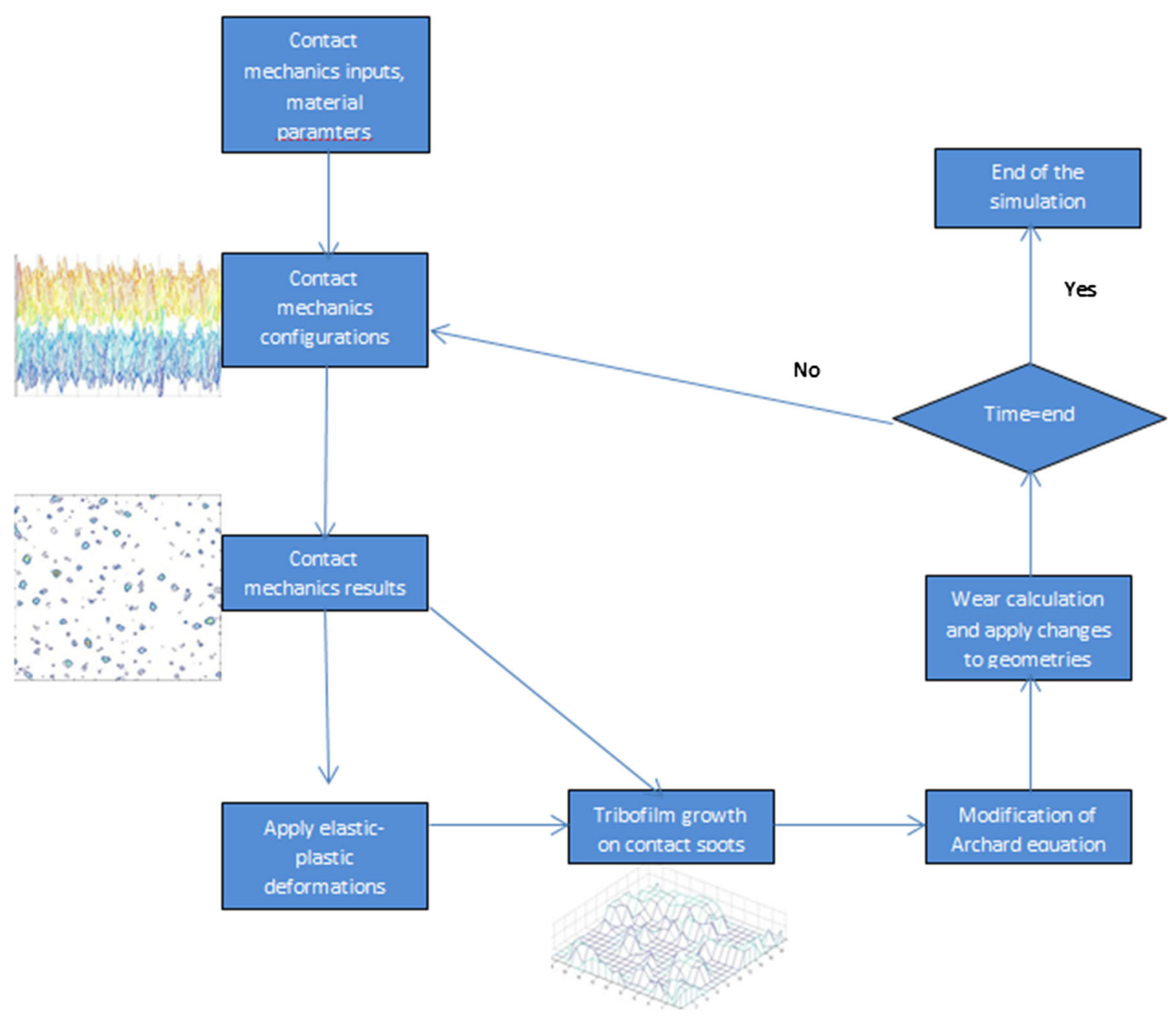

Fig. 1 Flowchart of the numerical model

thickness. The tribofilm removal constants $C_{3}$ and $C_{4}$ are also to be determined from calibration experiments.

\subsection{Wear Modelling}

The wear model proposed in [1] is based on the conventional Archard wear formulation; the local wear depth of each point of the surface is calculated using:

$\Delta h(x, y)=\frac{K}{H} \cdot P(x, y) \cdot \Delta t \cdot v$

in which $H, K, P$ and $v$ are the material hardness, dimensionless Archard's coefficient, local contact pressure and sliding speed, respectively, and $\Delta t$ is the time step in which contact occurs.

The wear coefficient is assumed to vary across the thickness of the tribofilm. It is assumed that in the areas where a tribofilm is formed, the coefficient of wear is less than in the areas where a tribofilm is not formed. The coefficient of wear is assumed to change linearly with tribofilm height. Assuming that the coefficient of wear is at its maximum for steel-steel contact and at its minimum when the tribofilm has its maximum thickness, the equation for calculating coefficient of wear is as follows:

$\mathrm{CoW}_{\text {tr }}=\mathrm{CoW}_{\text {steel }}-\left(\mathrm{CoW}_{\text {steel }}-\mathrm{CoW}_{\text {min }}\right) \cdot \frac{h}{h_{\max }}$

The relationship is represented graphically in Fig. 2. $\mathrm{CoW}_{\text {tr }}$ is the coefficient of wear for tribofilm with thickness $h$.

$\mathrm{CoW}_{\text {steel }}, \mathrm{CoW}_{\min }$ and $h_{\max }$ are coefficient of wear for steel and coefficient of wear corresponding to maximum ZDDP tribofilm thickness and maximum film thickness, respectively.

The wear modelled in this work is considered to be mild wear, which is the case for thick tribofilms. It was reported experimentally $[16,44-46]$ that, even in the areas where the tribofilm is fully formed, wear is occurring. It can be interpreted as partial removal of the tribofilm and at the same time formation of the film to restore the balance. Therefore, formation and removal of the tribofilm will lead 


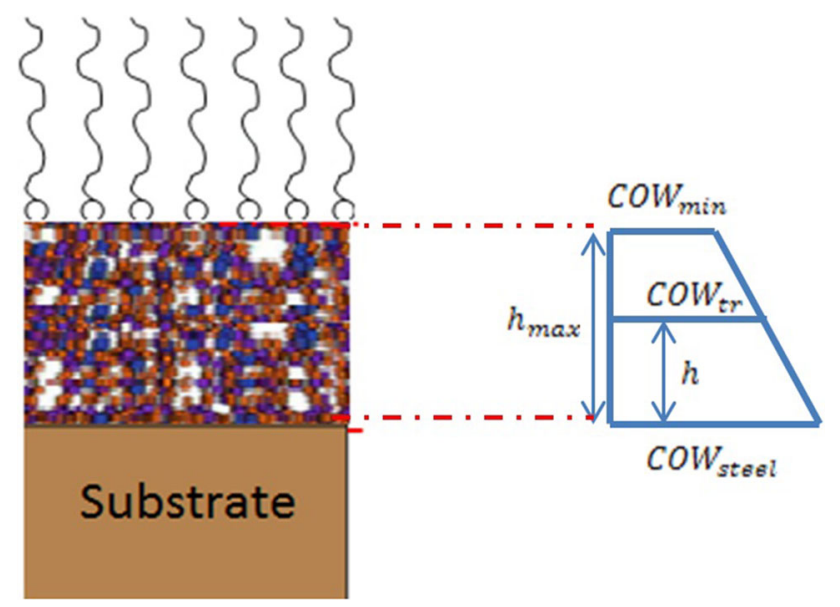

Fig. 2 Schematic of coefficient of wear variation with tribofilm thickness

to wear of the substrate [31]; however, this wear is much less than the wear resulting from solid-solid interactions. Note that this mechanism of wear does not apply in the case of inert substrates such as DLC, as mentioned in Sect. 1, but it is reasonable in the case of ZDDP tribofilms on steel surfaces.

Studies show that the concentration of substrate atoms decreases towards the top of the tribofilm produced by ZDDP $[29,31]$ on steel. If material detaches from the tribofilm due to the contact, some amount of the substrate atoms is removed from the surface. This decrease in the atomic concentration of the substrate as the distance from the substrate/tribofilm interface increases supports the fact that less wear of the substrate occurs if a thicker tribofilm exists. This mechanism was reported by Bosman et al. [31], who considered the volumetric percentage of Fe over the depth of the tribofilm and assumed lower concentration in upper layers of the tribofilm. It can be seen in Fig. 3 that the tribofilm can be removed as a result of the severe contact of the asperities and in this case a limited number of the substrate atoms present in the uppermost part of the tribofilm are detached from the surface. At the same time, more substrate atoms diffuse into the tribofilm and move towards the upper parts of the film to restore the chemical balance. This movement can be due to different mechanisms as explained in the introduction section. Replenishment of the tribofilm then might occur due to different surface phenomena including the tribochemical reactions and mechanical mixing due to combined effects of material removal and shear stress.

There is no experimental work reported in the literature presented thus far that provides a specific form for the variation in wear rate with local tribofilm thickness. The linear form assumed here is the simplest mathematical form that allows for a variation across the tribofilm as a result of the nonuniformity in the concentration of substrate ions across the tribofilm. This could be modified in future iterations of the model, should further experimental results become available, but the comparison with experiments in Sect. 4 indicates that Eq. (3) is a sufficient representation of the behaviour.

The wear discussed is the tribochemical that is wear in the presence of a tribofilm. It is therefore different from the concept of only fracture and removal of substrate due to mechanical rubbing. It should be noted that the formation of the tribofilm takes time as it takes time for the asperities in contact to be covered by a tribofilm. It is also shown in our simulation results (see Fig. 4) that the tribofilm gradually covers the surface in time and the inhomogeneous tribofilm is formed on the contacting asperities due to inhomogeneity of local properties of surfaces. In this sense, it takes some time for the coefficient of wear to reduce. The wear and plastic deformation happen severely at the beginning.

It is also important to note that this wear model does not necessarily predict that the thicker tribofilms observed in experiments result in less wear of substrate. There might be more removal of the tribofilm and therefore more removal of the substrate atoms because of the dynamic process of growth and regrowth of the tribofilm. The coefficient of wear used in this work is a local coefficient of wear which is changed in time because of changes in tribofilm thickness. It is very important to distinguish between these two aspects. The wear results measured in different experiments are shown in Sect. 3, and the validation of simulation results is reported in Sect. 4.

\subsection{Model Calibration Procedure}

There are several parameters in the complete model that require calibration before predictions of wear can be made. For the wear calculation part of the model, the parameters needed are the initial wear coefficient, $K$, and the minimum coefficient of wear, $\mathrm{CoW}_{\text {min }}$. These are determined using experimental results for one operating condition and then used for all other simulations under different conditions. For the tribofilm growth part of the model, the four parameters $x_{\text {tribo }}, h_{\max }, C_{1}$ and $C_{2}$ need to be determined for each set of experimental conditions in order to capture the tribofilm behaviour, which is different in each case. This is achieved by fitting Eq. (1) to experimental measurements of tribofilm thickness.

The procedure for determining the initial wear coefficient involves conducting simulations with different initial coefficients of wear to identify the coefficient value that exactly matches the wear behaviour observed in the calibration experiment. The same initial coefficient of wear 
Fig. 3 Justification of the wear model
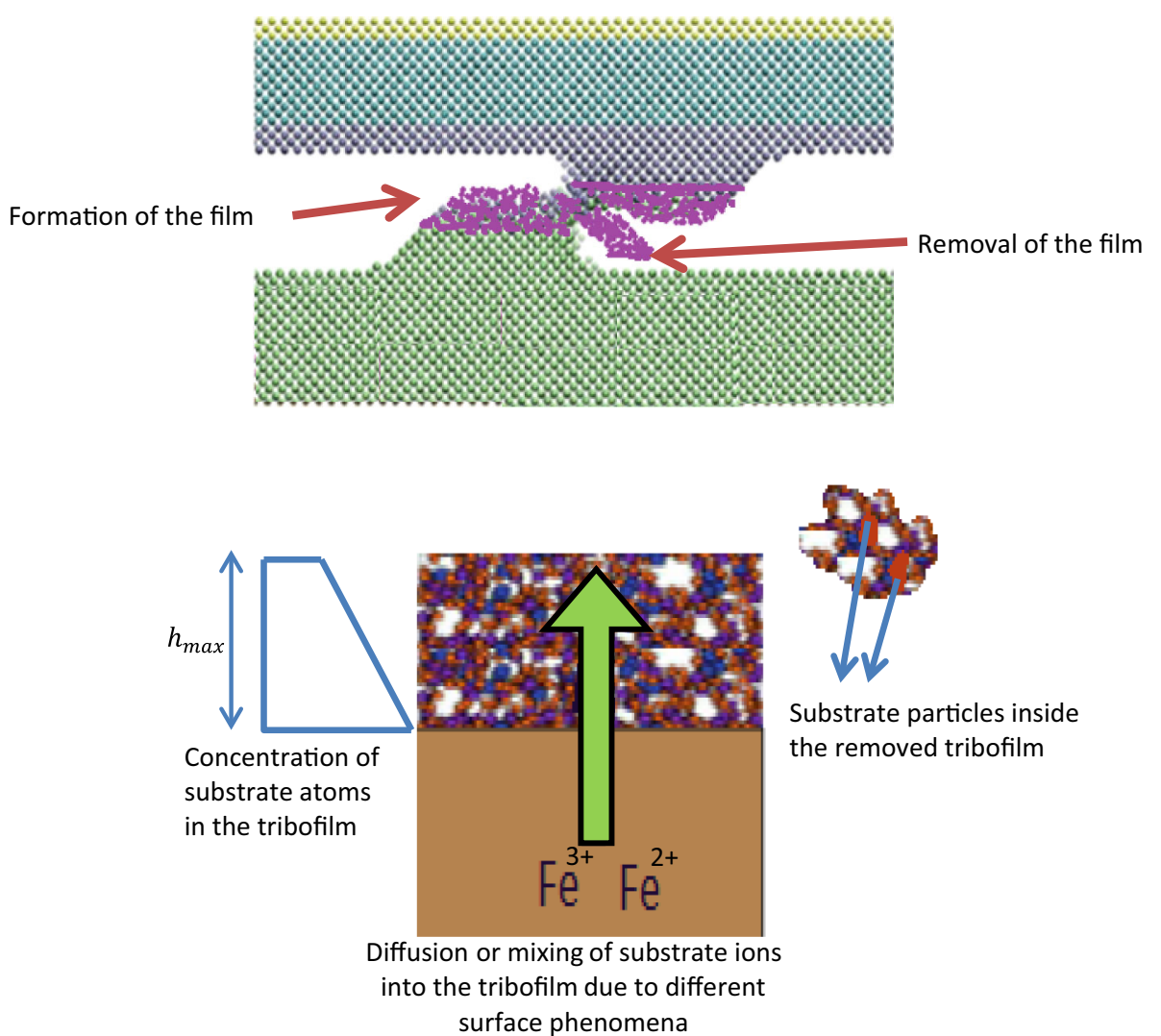

Substrate particles inside the removed tribofilm can then be used in all other simulations under different conditions.

For simplicity, the value of $\mathrm{CoW}_{\min }$ is chosen to be onetenth of the initial coefficient of wear for the case of steelon-steel contact. This is based on the experimental observations that wear in the presence of the ZDDP tribofilm has been reported to be approximately one-tenth of the wear in the absence of the ZDDP [46, 48-51]. The numerical prediction results confirm that this is a reasonable approximation.

\section{Experimental Procedure}

\subsection{Tribotest Set-up}

The experimental part of this study includes two parts. Firstly, tribotests were conducted to have rolling/sliding contacts in boundary lubrication using a mini-traction machine (MTM). The tribofilm thickness was measured using spacer layer interferometry to monitor the growth of the film. MTM-SLIM is capable of measuring tribofilm thickness in the range of 1-500 nm thicknesses in both EHL and boundary lubrication regime with an accuracy of $\pm 0.5 \mathrm{~nm}$ below $10 \mathrm{~nm}$ of thickness and \pm 2 above this level. The measurements were taken two times for each experiments, and the mean value is reported. As reported in [47], there is no need to have reference film thickness for calibration purposes which can make it significantly important in the case of measuring thin films. The tribometer set-up used in this work is shown schematically in Fig. 5. One of the key points in using MTM is that slide-toroll ratio (SRR) can be changed in the experiments and it is possible to run the experiment in a wide range of slide-toroll ratios $(0<\mathrm{SRR}<5)$.

In a standard configuration of the MTM, test specimens are a $19.05-\mathrm{mm}$ (3/4 inch) steel ball and a 46-mm-diameter steel disc. The ball and the disc are loaded, and they are connected to two different motors. The MTM is able to simulate a rolling/sliding contact. In a rolling/sliding contact, both surfaces (the ball and the disc) are moving. The sliding/rolling contact is simulated in the numerical model, and both surfaces are moving based on the slide-to-roll ratio (SRR) defined in the experiments. The frictional force is measured by a force transducer.

\subsection{Materials and Lubricating Oil}

The material used in this work was AISI 52100 steel for both ball and disc with a hardness of $6 \mathrm{GPa}$. The balls and discs are carefully cleaned by immersing in Isopropanol and petroleum ether before starting the experiments. All 


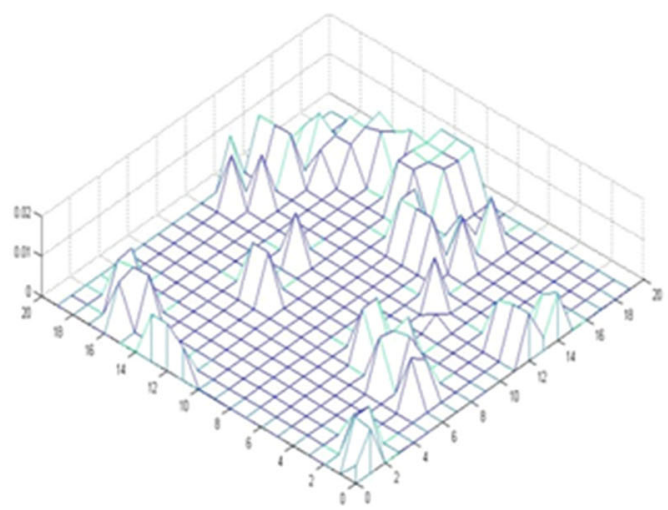

$1 \mathrm{~min}$

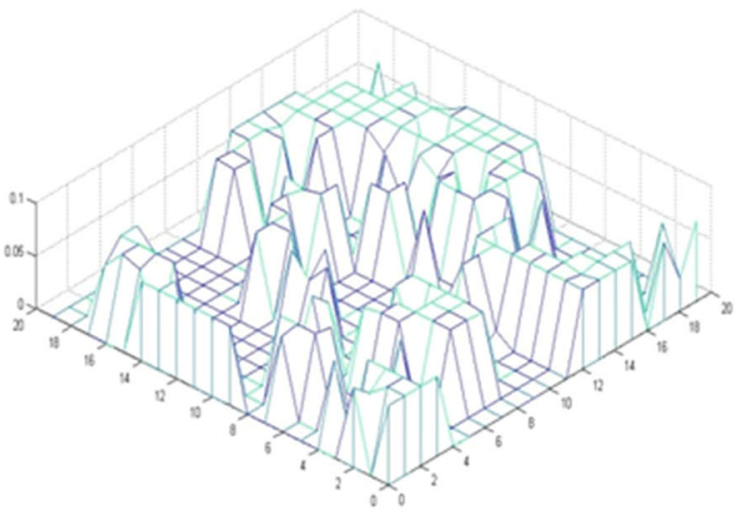

$30 \mathrm{~min}$

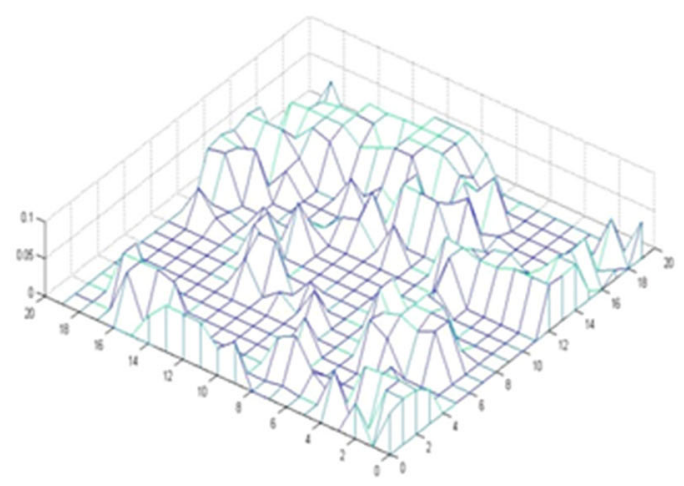

$10 \mathrm{~min}$

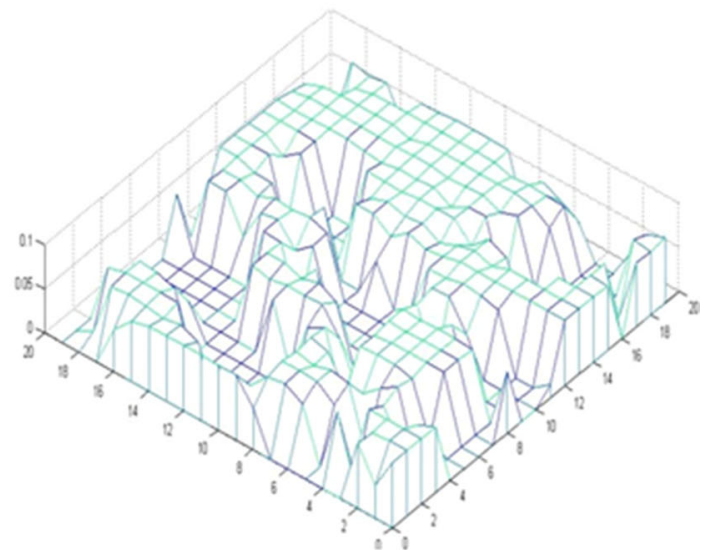

$60 \mathrm{~min}$

Fig. 4 Inhomogeneous growth of the tribofilm on rough surfaces at different times

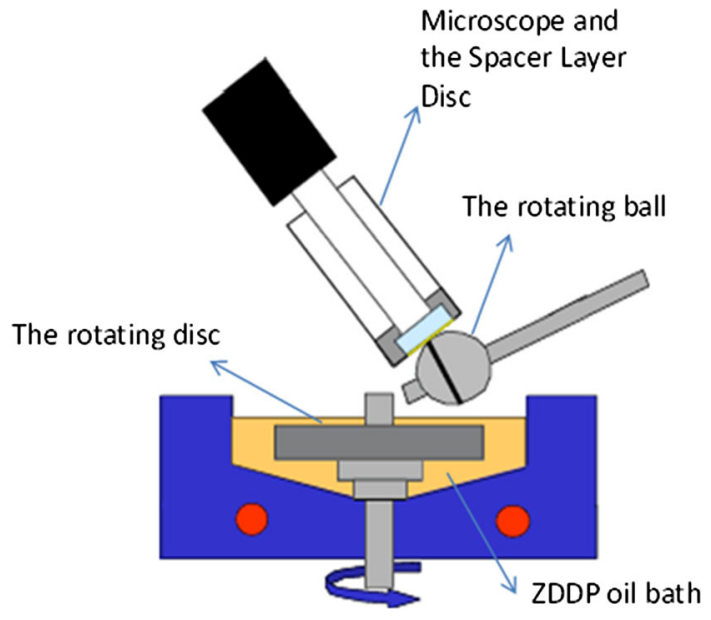

Fig. 5 Experimental set-up for MTM-SLIM

the experiments were conducted at an applied load of $60 \mathrm{~N}$, which corresponds to the maximum Hertzian pressure of $1.15 \mathrm{GPa}$. The materials used in the experiments are shown in Table 1.
Table 1 Material properties

\begin{tabular}{lr}
\hline Material properties & Value \\
\hline Hardness (GPa) & 6 \\
Elastic modulus (GPa) & 210 \\
Ball surface roughness (nm) & 20 \\
Disc surface roughness $(\mathrm{nm})$ & 130 \\
\hline
\end{tabular}

Experiments were carefully designed to study wear in boundary-lubricated contact at different ZDDP concentrations and temperatures, and a small entrainment speed was chosen for this purpose. This experimental matrix is chosen to produce several different growth behaviours of ZDDP tribofilm on steel surfaces and at the same time to be able to measure wear at different times corresponding to those growth behaviours. The lubricating oil is selected to be Poly- $\alpha$-Olefin (PAO) with 0.5 and $1 \%$ wt ZDDP as antiwear additive. The working conditions and the corresponding $\lambda$ ratios are reported in Table 2 . 
Table 2 Working parameters

\begin{tabular}{ll}
\hline Parameters & Value \\
\hline Maximum contact pressures $(\mathrm{GPa})$ & 1.15 \\
Temperature $\left({ }^{\circ} \mathrm{C}\right)$ & $60,80,100$ \\
Entrainment speed $\left(\frac{m}{s}\right)$ & 0.1 \\
SRR & $5 \%$ \\
Test durations (min) & $30,45,120$ \\
$\lambda$ ratios & Around 0.04 \\
Oil used & PAO $+0.5 \%$ wt ZDDP \\
& PAO $+1 \%$ wt ZDDP \\
\hline
\end{tabular}

\subsection{Wear Measurement}

The samples were analysed after each experiments, and wear measurements were taken by an interferometer. Samples are taken out of the experimental set-up after the complete tribotests. The tribofilm formed on the surfaces are carefully cleaned. A white-light interferometer is then used to analyse the profile of the wear track. Two-dimensional and three-dimensional images were taken from the wear track, and the average wear depth of different areas inside the wear track is calculated. The experiments were repeated two times for each working condition, and wear was measured in all cases. The wear reported results include the error bars and the variation in the experimental results from the mean value. It should be also noted that the wear depth was measured for six different points inside the wear track for each experiment and the average value was reported for the analysis.

Experiments for two different ZDDP concentrations and temperatures were conducted at different times to be able to test the model and the effect of evolution of the ZDDP tribofilm on the wear of the system.

\section{Results}

\subsection{Tribofilm Thickness Results}

MTM-SLIM configuration results are shown in this section for two ZDDP concentrations at three temperatures and three times. Thickness measurements for $1 \%$ wt ZDDP concentrations in oil at two temperatures of 60 and $100{ }^{\circ} \mathrm{C}$ for three different test durations are shown in Figs. 6 and 7. In addition, the measurement results with the same concentration for different temperatures for 2-h test duration are plotted in Fig. 8. Spacer Layer imaging results are also plotted for $0.5 \%$ wt ZDDP concentration in oil at three different temperatures of 60,80 and $100{ }^{\circ} \mathrm{C}$ in Fig. 9 .

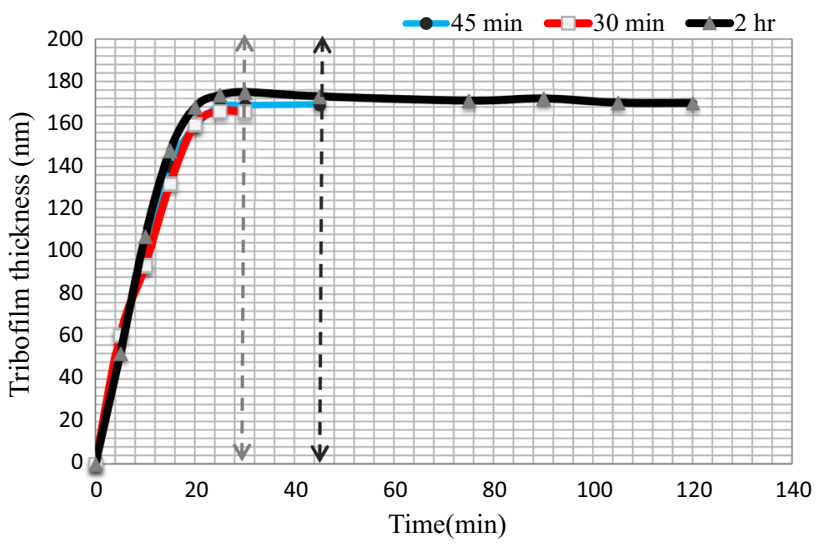

Fig. 6 Tribofilm thickness measurements for $100{ }^{\circ} \mathrm{C}$ at different times

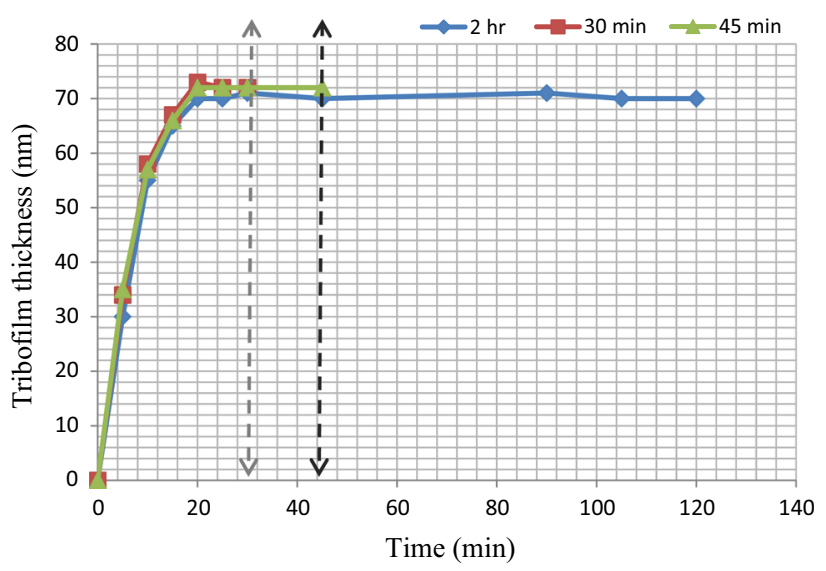

Fig. 7 Tribofilm thickness measurements for $60{ }^{\circ} \mathrm{C}$ at different times

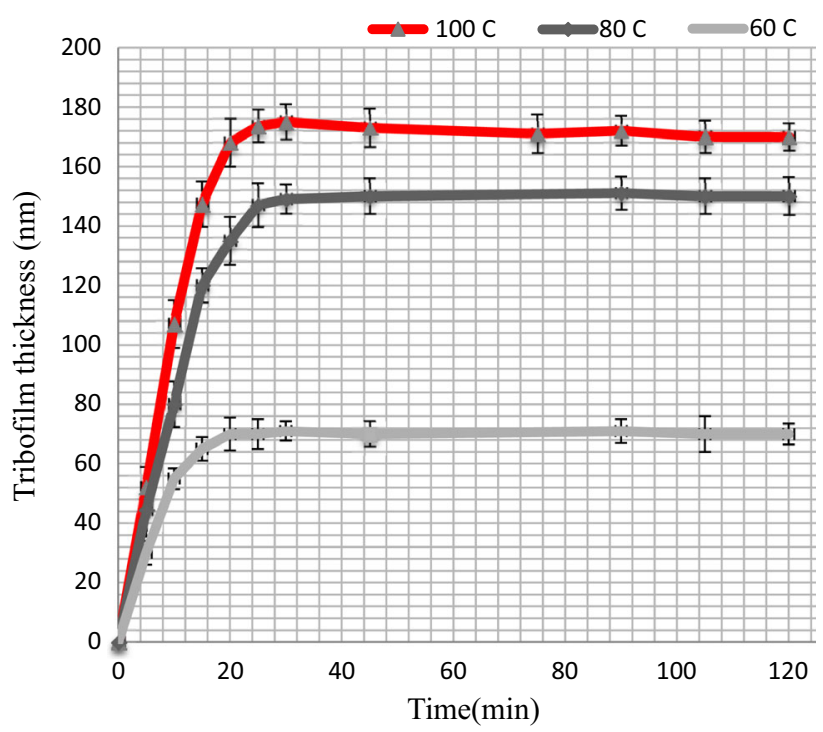

Fig. 8 Tribofilm thickness measurements for different temperatures for $1 \%$ wt ZDDP in oil 


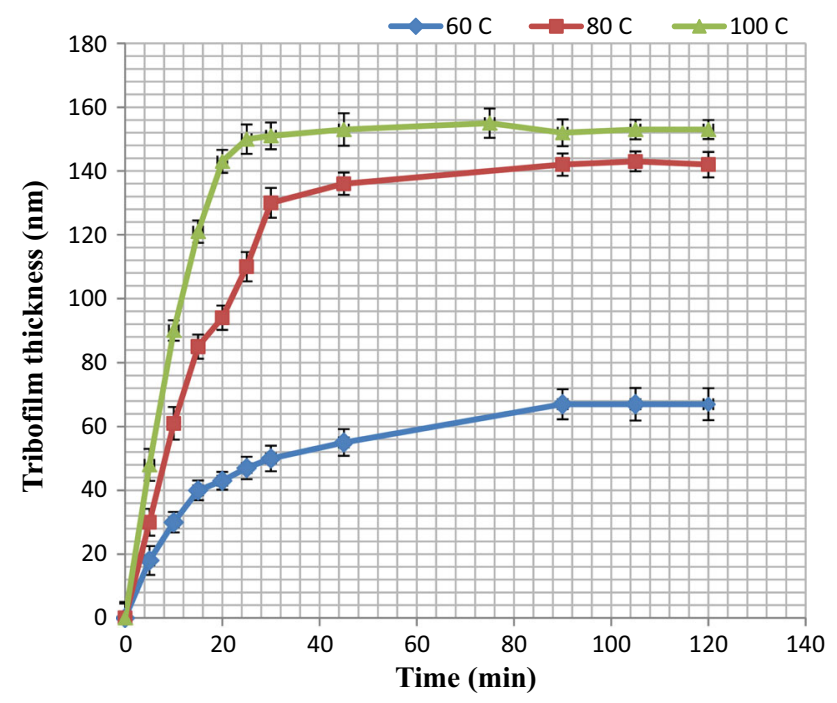

Fig. 9 Tribofilm thickness measurements for different temperatures for $0.5 \%$ wt ZDDP in oil

The tribofilm measurement results are used to calibrate the tribochemical model of Eq. (1), and the calibrated parameters are reported in Table 3. The goodness of the fittings is also shown in Fig. 10 for one case of $1 \% \mathrm{wt}$ ZDDP in oil. Figure 10 shows the tribofilm thickness predicted by the simulation and measured experimentally for the three temperatures $\left(60,80\right.$ and $\left.100{ }^{\circ} \mathrm{C}\right)$ for $1 \% \mathrm{wt}$ ZDDP. There is very good agreement between simulation and experiment, and both show that the tribofilm formed under these different conditions has a different thickness. The tribochemical model predicts the growth of the tribofilm at asperity scale. Therefore, the next step would be to examine the effect of this formed tribofilm on wear of the system using the proposed wear model. Wear measurement results are shown in the next section, and the predicted numerical results are reported in Sect. 4.

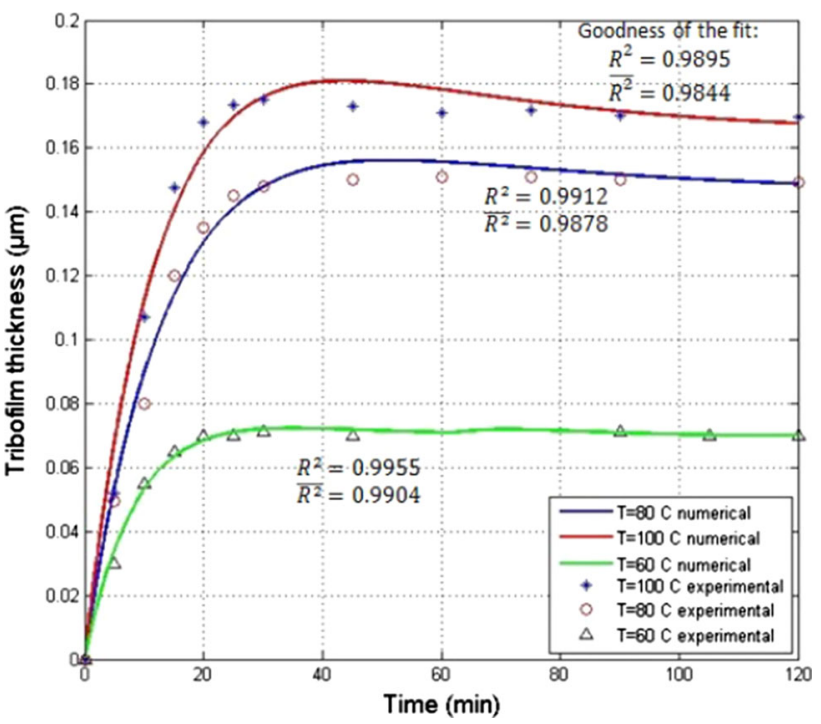

Fig. 10 Example of numerical and experimental tribofilm growth for $1 \%$ wt ZDDP in oil at three different temperatures

\subsection{Wear Results}

White-light interferometry was used to measure wear on the discs. An example of wear measurement images is shown in Fig. 11.

The samples were carefully cleaned by EDTA. Previous works have shown that ZDDP tribofilm on the wear scar can lead to misleading wear measurements when whitelight interferometry is used because of their transparent characteristics.

The wear analysis in this work is based on the average wear depth profile and is compared to the numerical results. Wear depth is measured by comparing the average heights of points inside and outside the wear track. An example of this comparison is shown in Fig. 12.

Table 3 Numerical inputs and calibrated parameters

\begin{tabular}{llllll}
\hline Parameter & $1 \%$ wt ZDDP & & $0.5 \%$ wt ZDDP & Description \\
\cline { 2 - 4 } & $100_{C}^{0}$ & $80_{C}^{0}$ & $60_{C}^{0}$ & $100_{C}^{0}$ & \\
\hline $\mathrm{K}$ & $5.45 \times 10^{-8}$ & $5.45 \times 10^{-8}$ & $5.45 \times 10^{-8}$ & $5.45 \times 10^{-8}$ & Initial dimensionless wear coefficient for steel \\
$C O W_{\text {min }}$ & $5.45 \times 10^{-9}$ & $5.45 \times 10^{-9}$ & $5.45 \times 10^{-9}$ & $5.45 \times 10^{-9}$ & Dimensionless wear coefficient for maximum film thickness \\
$h_{\max }$ & $250 \mathrm{~nm}$ & $200 \mathrm{~nm}$ & $150 \mathrm{~nm}$ & $250 \mathrm{~nm}$ & Maximum local tribofilm thickness in the formation process \\
$x_{\text {tribo }}$ & $1.66 \times 10^{-16}$ & $1.66 \times 10^{-16}$ & $1.66 \times 10^{-16}$ & $1.30 \times 10^{-16}$ & Tribofilm formation rate constant \\
$C_{1}$ & 0.08566 & 0.05432 & 0.08052 & 0.08052 & Tribofilm removal constant \\
$C_{2}$ & 0.000457 & 0.0004022 & 0.0004033 & 0.000406 & Tribofilm removal exponential factor \\
$E_{1}, E_{2}$ & $209 \mathrm{GPa}$ & $209 \mathrm{GPa}$ & $209 \mathrm{GPa}$ & $209 \mathrm{GPa}$ & Young's modulus of two surfaces \\
$v_{1}, v_{2}$ & 0.3 & 0.3 & 0.3 & 0.3 & Poisson ratio \\
$H_{\text {steel }}$ & $6 \mathrm{GPa}$ & $6 \mathrm{GPa}$ & $6 \mathrm{GPa}$ & $6 \mathrm{GPa}$ & Hardness of the steel substrate \\
$H_{\text {tr }}$ & $2 \mathrm{GPa}$ & $2 \mathrm{GPa}$ & $2 \mathrm{GPa}$ & $2 \mathrm{GPa}$ & Hardness of the tribofilm at steady-state tribofilm thickness \\
\hline
\end{tabular}



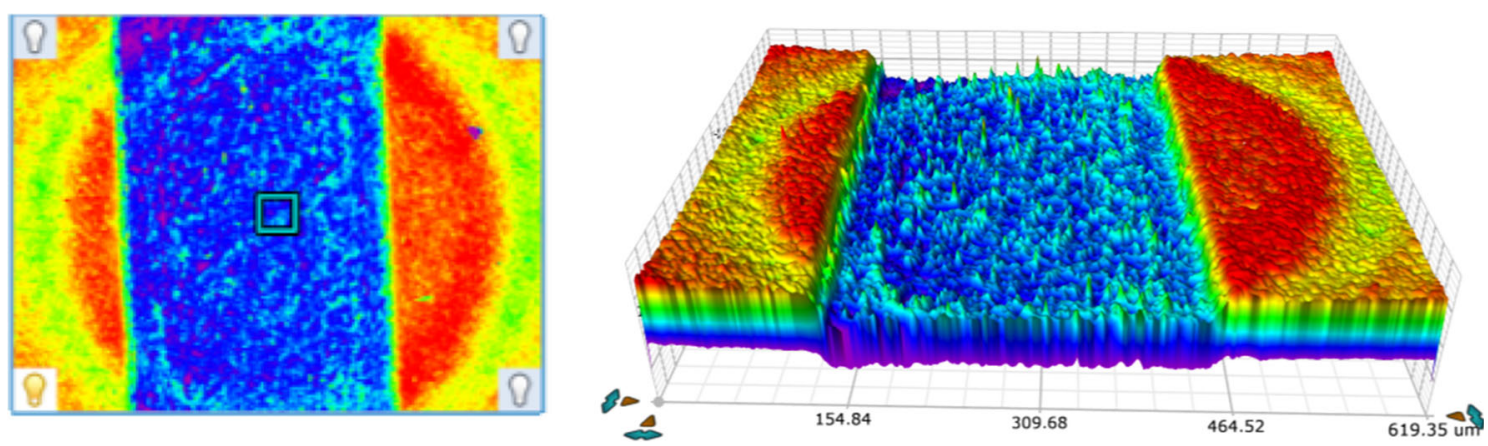

Fig. 11 Two-dimensional and three-dimensional images of wear track

Fig. 12 Two-dimensional wear track image and the image profile of the surface after the experiment
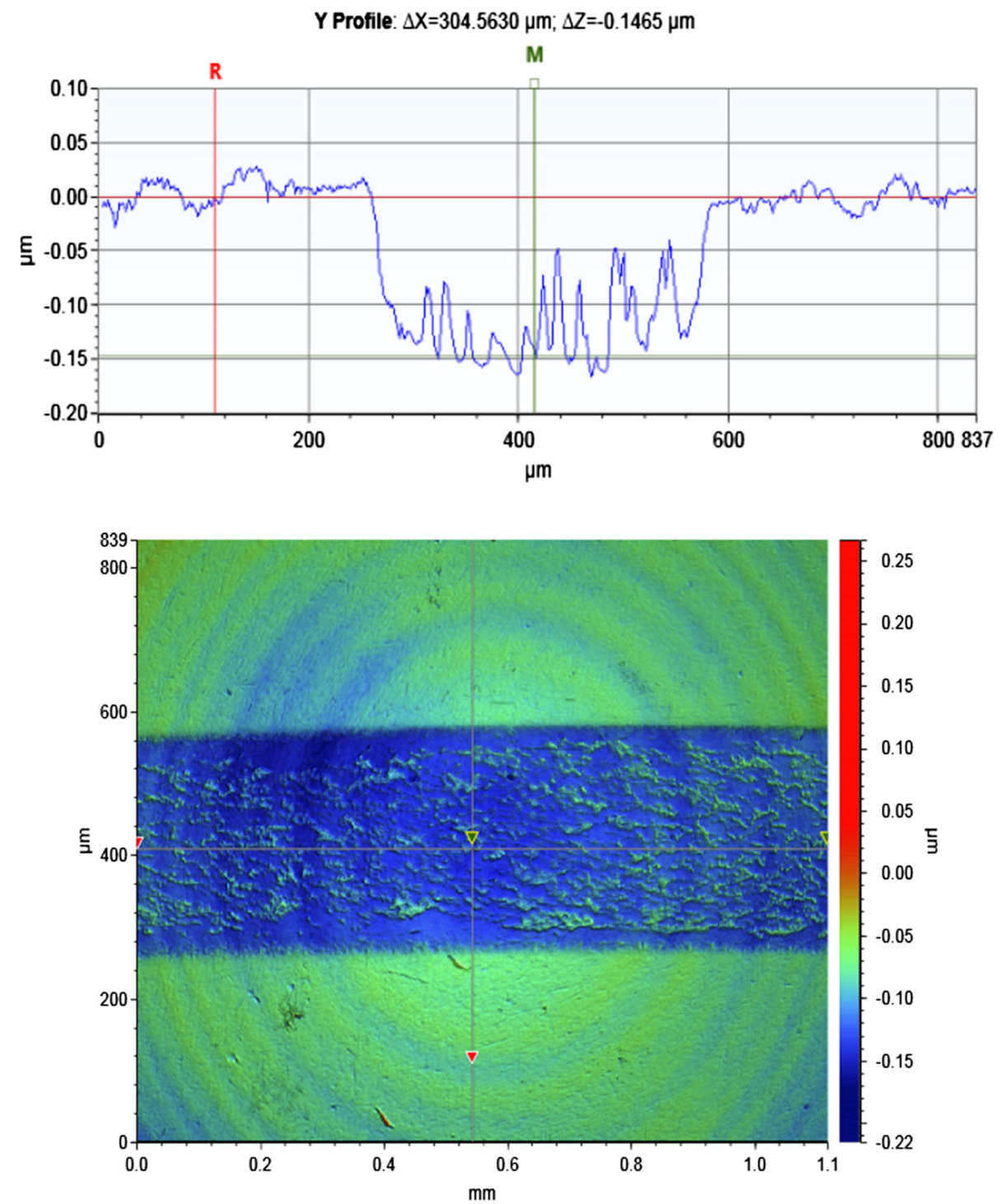

The measurement results for different working conditions as reported in Table 2 are shown in Fig. 13 for $1 \%$ wt ZDDP in oil and Fig. 14 for $0.5 \%$ wt ZDDP which give the wear depth measured for different samples. The experiments were conducted for different times for $1 \% \mathrm{wt}$ ZDDP to see the evolution of wear and validating the model, but only 2-h experiments were carried out for $0.5 \%$ wt ZDDP in the oil. 


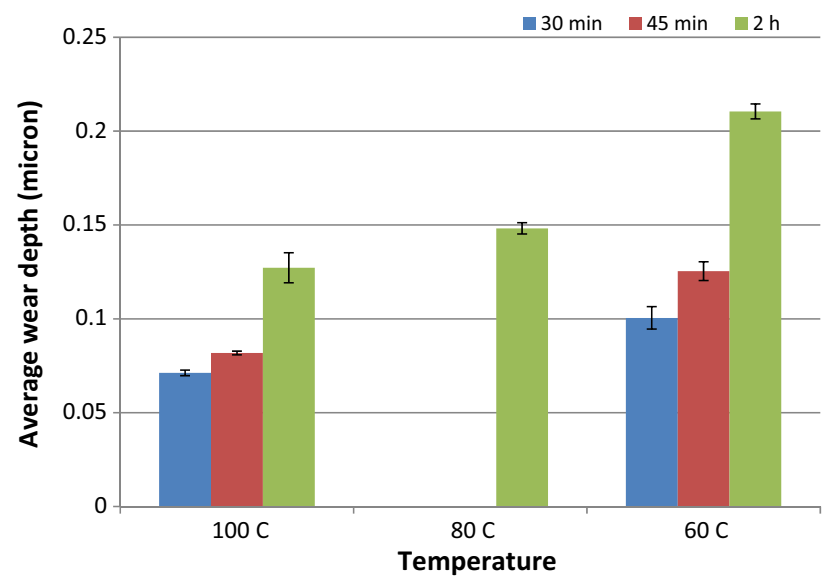

Fig. 13 Wear measurements for different temperatures and different times for $1 \%$ wt ZDDP in oil

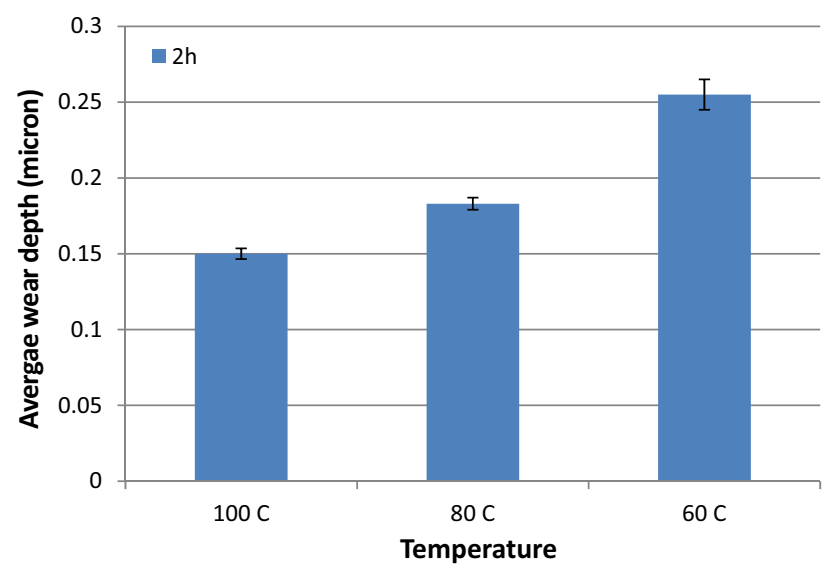

Fig. 14 Wear measurements for different temperatures for $1 \% \mathrm{wt}$ ZDDP in oil at $2 \mathrm{~h}$

From the comparison of the experimental results, it can be interpreted that a higher concentration of ZDDP in the oil increases the growth rate of the ZDDP tribofilm. It is also shown that a higher concentration of ZDDP results in less wear in the system. These conditions are simulated by the model, and the results are reported in the next section.

\subsection{Numerical Results and Discussion}

The experimental wear depth measurement for $80{ }^{\circ} \mathrm{C}$ at $2 \mathrm{~h}$ was used to calibrate the wear model as described in Sect. 2.2. The initial coefficient of wear found agreed well with values reported in the literature [30-32]. Wear is calculated at every time step of the simulation using the wear model described in Sect. 2.1, and plastic deformation is calculated in the elastic-perfectly plastic contact model. The amount of wear is accumulated in time at every asperity in contact, and the wear depth can be calculated at the end of simulation. The experiments reported in Sect. 3

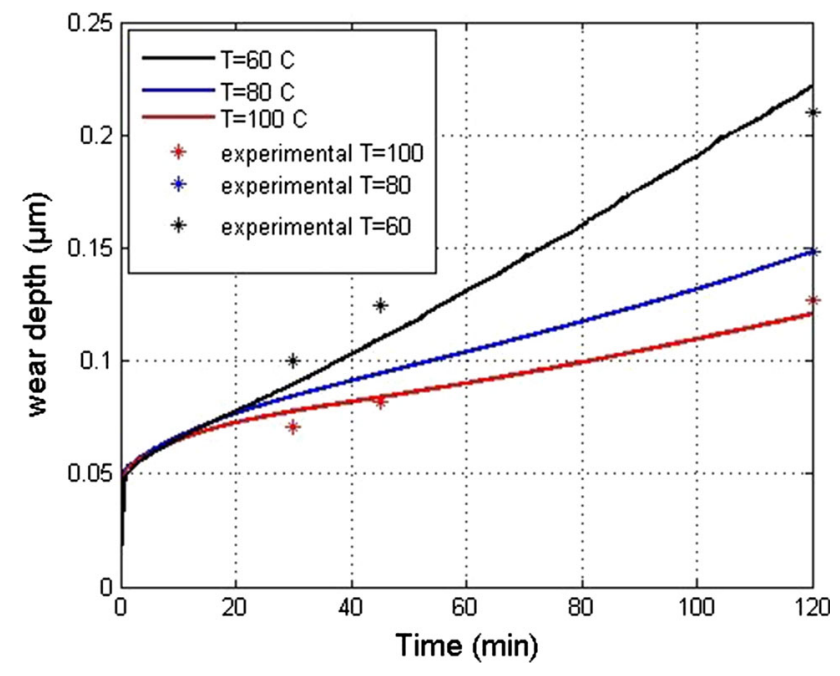

Fig. 15 Simulation of wear for different temperatures at $2 \mathrm{~h}$ for $1 \%$ wt ZDDP in oil

were simulated via the model, and the predicted wear depth as a function of time is shown in Fig. 15 for $1 \%$ wt ZDDP in oil and Fig. 16 for $0.5 \%$ wt ZDDP. This strategy shows that if the model is able to capture the tribofilm growth on the surface, it is also able to capture wear in the systems with this specific mechanism. The authors believe that this model in combination with the experiments can open new insights into the mechanisms of wear reduction in ZDDP on steel surfaces and relate it to the tribofilm formation and removal properties and can be extended to systems where tribochemical reactions form reactive layers and these layers offer a physical barrier to the surface. This would be the case for most P-containing antiwear additives. For comparison with experiments, calculations of wear depth and tribofilm thickness are made by averaging values over the entire computational surface. It must be noted that in the previous work by the authors [1] the tribofilm growth model was calibrated using experimental results from the literature [43] which were obtained using a WAM (Wedaven Associates Machine) and spacer layer interferometry. The calibration parameters were then used to simulate the model to see the pattern of surface topography and wear of the system. No validation of such physical parameters was then reported, and only the numerical model development and its capabilities were studied. In this work, experiments were conducted on MTM and the tribofilm growth results are based on the new measurements.

Tribofilm thickness experimental results are used to capture the growth behaviour by setting the simulation values with respect to the experimental results. It is important to notice that once the tribofilm behaviour is captured, the model is able to predict the wear behaviour for the case of ZDDP on steel surfaces. So far in this research, capturing the tribofilm behaviour was dependent 


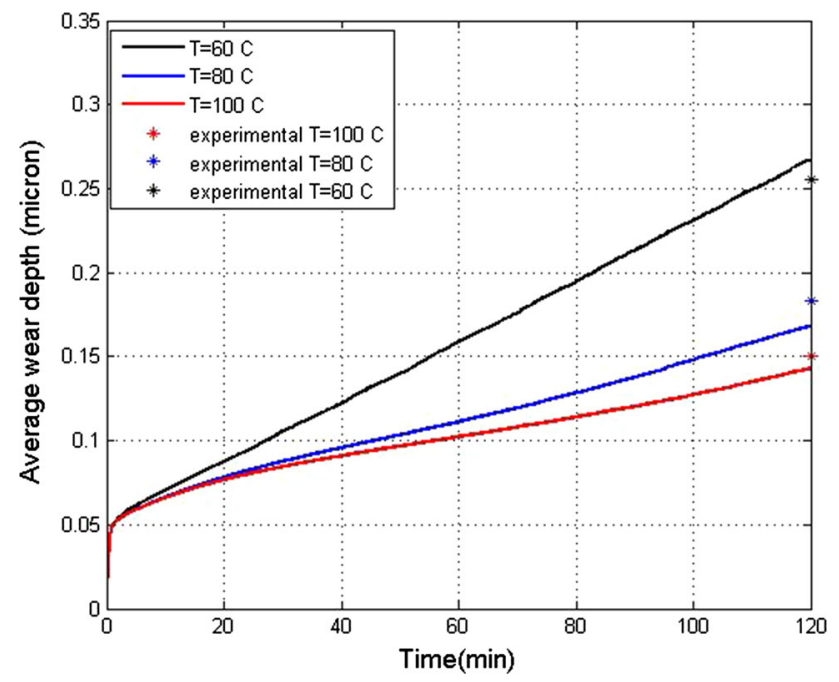

Fig. 16 Simulation of wear for different temperatures at $2 \mathrm{~h}$ for $1 \%$ wt ZDDP in oil

on the experimental results due to the lack of comprehensive analytical understanding of the real mechanisms of tribofilm formation and removal. Despite all the complexities, such simplified semi-analytical models for tribofilm growth can be good starting points for the problem. As explained in detail in the previous work [1], there is more need for experimentation to develop the proposed tribofilm growth even further. The parameters used in the tribofilm growth model such as $x_{\text {tribo }}, h_{\max }, C_{1}$ and $C_{2}$ for different sets of experiments are reported in Table 3. It can be seen from Table 3 that the fitting parameters are different for different experiments and this is not surprising due to the different growth behaviour in each experiment. The calibration results in this work reported in Table 3 are in line with the theories explained in [1]. It can be seen that $x_{\text {tribo }}$ is the same for different temperatures of the same condition. It is also reasonable to have smaller $x_{\text {tribo }}$ for lower concentration of ZDDP in the oil. These results are in agreement with the concept of $x_{\text {tribo }}$ which was explained in detail in [1]. In principle, this term relates to the proportion of transition states in the tribochemical reaction that result from mechanical activation; in practice, it is a fitting parameter to be calibrated via experiments providing in situ measurements of tribofilm thickness. The advantage of this model is the ability to link to component scale measurements. It must be noted that the work strongly supports the fact the tribofilm reactions need shear stress to initiate. The temperature dependency of the kinetics is not exponential-like conventional Arrhenius-type equations. The term $x_{\text {tribo }}$ is independent of the temperature, and it is confirmed in the numerical results reported in Table 3. It shows that concentration of lubricant additives can be considered in the growth modelling of their tribofilm. Since

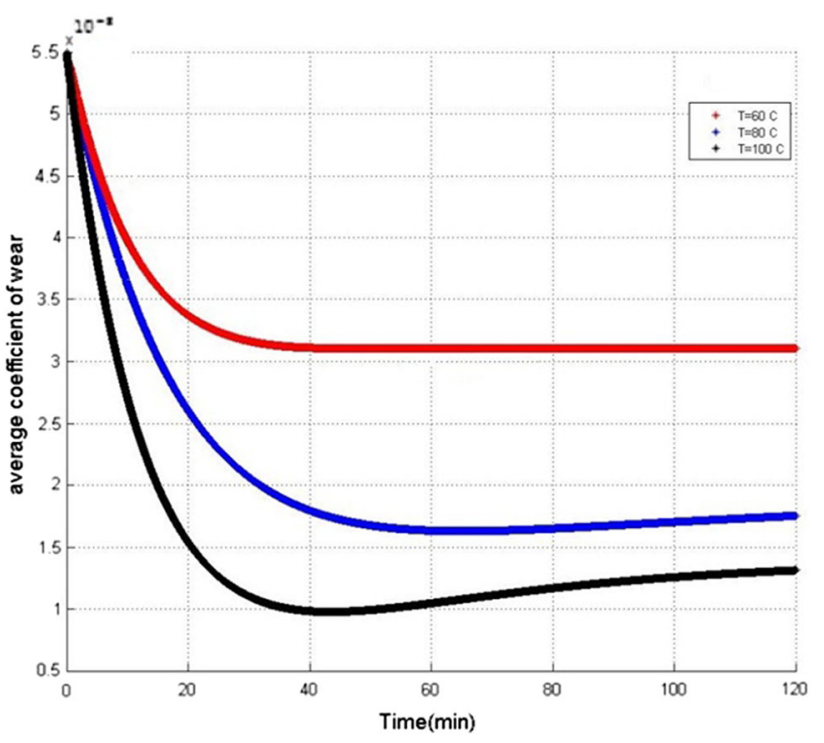

Fig. 17 Variation in the average coefficient of wear with time for different temperatures for $1 \%$ wt ZDDP in oil

this is not the focus of this work, further discussion on the growth model is not presented here.

As explained in Sect. 2.1, the coefficient of wear in the simulation is time and position dependent. Therefore, the average coefficient of wear at each time in the simulation can be obtained by averaging the values for coefficient of wear for all contacting points. The variation in the average coefficient of wear with time for different temperatures in the case of $1 \%$ ZDDP in the oil is plotted in Fig. 17. It can be interpreted from the results that growth of the tribofilm on the contacting spots can reduce the average wear coefficient and that results in the overall wear reduction. The average wear coefficient tends to stabilize when the tribofilm thickness stabilizes and this is where the steadystate wear can start.

The predicted pattern of wear depth seen in Figs. 15 and 16 shows that a relatively fast plastic deformation happens in the beginning of the contact and the rate of the wear reduces as the rate of plastic deformation reduces. The wear of material still remains and is responsible for the reduction in depth of the contact. Formation of the tribofilm on the contact spots results in the reduction of wear rate and is responsible for less wear being observed in numerical results. The amount of wear observed experimentally after 30 and $45 \mathrm{~min}$ at 100 and $60{ }^{\circ} \mathrm{C}$ for $1 \% \mathrm{wt}$ ZDDP in oil is also shown as discrete data points in Fig. 15. The simulation predictions show reasonably good agreement with the experimental measurements (see also Table 4 for comparison of the data values).

Figures 10, 15 and 16 together therefore highlight that the effect of the ZDDP tribofilm on the coefficient of wear is well captured by the model. 
Table 4 Comparison between experimental measurements and numerical wear depth calculations

\begin{tabular}{|c|c|c|c|}
\hline & Test (min) & $\begin{array}{l}\text { Experimental } \\
\text { wear depth } \\
\text { measurements }(\mu \mathrm{m})\end{array}$ & $\begin{array}{l}\text { Numerical } \\
\text { wear depth } \\
\text { results }(\mu \mathrm{m})\end{array}$ \\
\hline \multirow[t]{7}{*}{$1 \%$ wt ZDDP } & $100_{C-}^{0} \_30$ & 0.0712 & 0.0778 \\
\hline & $100_{C-}^{0}-45$ & 0.0818 & 0.0839 \\
\hline & $100_{C-120}^{0}$ & 0.1272 & 0.1208 \\
\hline & $80_{C-1}^{0} 120$ & 0.1482 & 0.1484 \\
\hline & $60_{C \_-30}^{0}$ & 0.1006 & 0.0917 \\
\hline & $60_{C-}^{0} \_45$ & 0.1252 & 0.1121 \\
\hline & $60_{C-1}^{0} 120$ & 0.2102 & 0.2215 \\
\hline \multirow[t]{3}{*}{$0.5 \%$ wt ZDDP } & $100_{C-}^{0} 120$ & 0.1505 & 0.1430 \\
\hline & $80_{C-1}^{0} 120$ & 0.1830 & 0.1682 \\
\hline & $60_{C-}^{0} 120$ & 0.2550 & 0.2676 \\
\hline
\end{tabular}

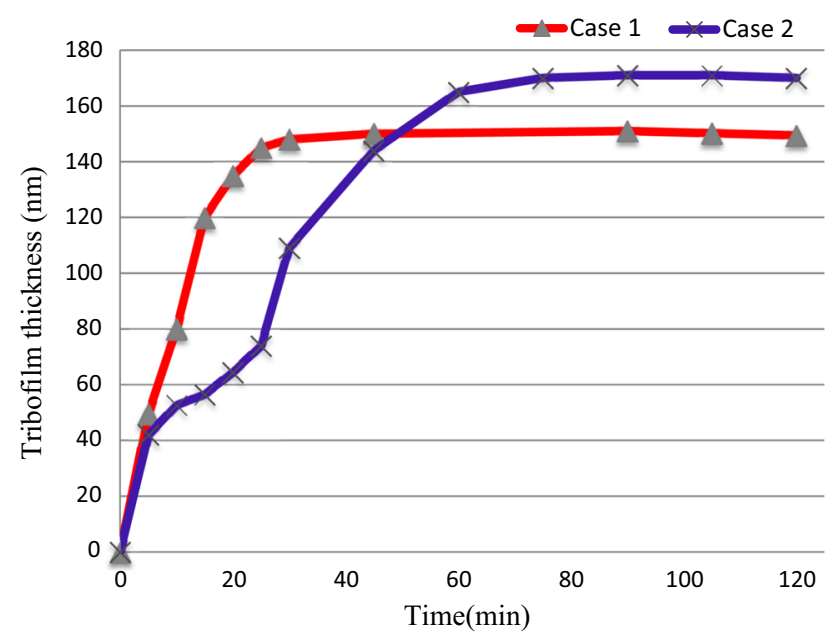

Fig. 18 An example of two experimental cases with different tribofilm growth rates and different tribofilm steady-state thickness

The tribochemical wear model tested in this work can be applied to systems similar to the one reported here, where a reacted film with varying chemistry through the thickness is formed. As discussed in Sect. 2.1, it is possible to have a thick antiwear tribofilm yet a high wear of the surface. As the tribofilm starts to grow on the surface, the rate of this growth plays a significant role in the rate of reduction in the coefficient of wear. The thickness reported in most experimental studies is the steady-state tribofilm thickness, but the coefficient of wear in this work is a function of time and changes with the gradual changes in the thickness of the tribofilm. Therefore, it is very possible to have a thicker tribofilm in the simulation at steady state while also having a higher wear. A visual example of this difference is shown in Fig. 18.
Table 5 Wear depth results for different cases in Fig. 18

\begin{tabular}{ll}
\hline Case & Wear depth $(\mu \mathrm{m})$ \\
\hline 1 & 0.1355 \\
2 & 0.1422 \\
\hline
\end{tabular}

It can be seen in Fig. 18 that in case 1 there is faster growth of the tribofilm at the beginning, which can result in faster reduction in the wear coefficient. It is also obvious that tribofilm thickness in the steady state is thicker for case 2. Wear calculations show that case 2 has a higher wear in comparison with case 1 and the results are shown in Table 5. This example highlights the fact that a thicker tribofilm in the steady state does not guarantee less overall wear of the system.

The tribofilm thickness measurements resulting from spacer layer interferometry were used to calibrate the tribochemical model of Eq. (12). Simulations were carried out using the calibrated parameters and working conditions. The simulation results show that the assumption of a lower time and spatially dependent coefficient of wear for thicker tribofilms is reasonable for the case of different temperatures and different concentrations of ZDDP in the oil. It can be seen in Figs. 15 and 16 that at the start of the tribocontact, simulations show almost the same wear because of high plastic deformation. At some point, when the tribofilm starts to grow, and because of variable reaction rates (indicated by $x_{\text {tribo }}$ values), the coefficient of wear starts to decrease and the rate of this decrease depends on temperature and concentration of additive. This fact is also confirmed in Fig. 17. The experimental results support the model.

\section{Conclusions}

The recent mechanochemical model for boundary lubrication developed by Ghanbarzadeh et al. [1] has been tested against new experiments, focusing particularly on the wear prediction capabilities of the model. The wear model is applied locally at the asperity scale, where a local coefficient of wear varies linearly with the current value of the local tribofilm thickness. The model is time dependent, with the surface topography updated at each time step as a result of plastic deformation and tribofilm formation, and the local wear coefficient changes in response to changes in the thickness of the tribofilm at every time step. Following calibration of the wear model parameters against experiments under one set of conditions, simulations under different conditions are tested against further experiments. Prediction of both the tribofilm growth and the wear depth as a function of time shows good agreement with experimental observations. 
The results support the argument that wear can happen because of the removal of the substrate atoms present in the tribofilm due to different tribochemical phenomena, and the dynamic loss of material within the tribofilm throughout the growth on the contacting asperities. The wear rate under such conditions is much lower than that in the absence of a tribofilm, and the model captures this distinction, predicting faster wear in the early stages of the test where the tribofilm has yet to form.

Although the coefficient of wear in the model decreases with increasing tribofilm thickness, it is seen that having a thicker tribofilm at steady state does not guarantee lower overall wear. Since the model captures the complete dynamics of the system, from bare surface through to constant average tribofilm thickness, it can be seen how the initial rate of tribofilm formation, influenced by temperature and local surface topography, affects the overall average wear depth seen in tribological tests. Example simulations are shown in which the wear depth is greater for a case with a thicker tribofilm.

The model tested in this work does not necessarily capture the wear mechanisms for all boundary lubrication systems such as DLCs and Al/Si alloys, but the framework can be a good flexible approach to test different mechanisms. There is still a need for more experimental evidence to see how tribofilm formation and/or removal is responsible for the wear of the boundary-lubricated systems for ZDDP antiwear additive on steel surfaces. Hence, this model will be a foundation for finding the correlation between tribofilm growth and wear, and more experiments are currently being carried out by authors. The study of tribofilm removal and its chemical and physical effects on wear of the boundary-lubricated contacts is the subject of the ongoing research.

The model tested shows good agreement with experiments, indicating that, once calibrated, it has predictive capabilities that provide a beneficial tool for further exploration of boundary-lubricated systems.

Acknowledgments This study was funded by the FP7 programme through the Marie Curie Initial Training Network (MC-ITN) entitled "ENTICE - Engineering Tribochemistry and Interfaces with a Focus on the Internal Combustion Engine" [290077] and was carried out at University of Leeds and SKF Engineering and Research Centre. The authors would like to thank to all ENTICE partners for kind discussions on the topic and the methodology.

Open Access This article is distributed under the terms of the Creative Commons Attribution 4.0 International License (http://crea tivecommons.org/licenses/by/4.0/), which permits unrestricted use, distribution, and reproduction in any medium, provided you give appropriate credit to the original author(s) and the source, provide a link to the Creative Commons license, and indicate if changes were made.

\section{References}

1. Ghanbarzadeh, A., Wilson, M., Morina, A., Dowson, D., Neville, A.: Development of a new mechano-chemical model in boundary lubrication. Tribol. Int. 93(2), 573-582 (2016)

2. Archard, J.: Contact and rubbing of flat surfaces. J. Appl. Phys. 24, 981-988 (1953)

3. Sullivan, J.L.: Boundary lubrication and oxidational wear. J. Phys. D Appl. Phys. 19(10), 1999 (1986)

4. Stolarski, T.A.: A system for wear prediction in lubricated sliding contacts. Lubr. Sci. 8(4), 315-351 (1996)

5. Greenwood, J.A., Williamson, J.B.P.: Contact of nominally flat surfaces. Proc. R. Soc. Lond. A 295(1442), 300-319 (1966)

6. Zhang, H., Chang, L., Webster, M.N., Jackson, A.: A microcontact model for boundary lubrication with lubricant/surface physiochemistry. J. Tribol. 125(1), 8-15 (2003)

7. Carslaw, H.S., Jaeger, J.C.: Heat in solids. (1959)

8. Bortoleto, E.M., Rovani, A.C., Seriacopi, V., Profito, F.J., Zachariadis, D.C., Machado, I.F., Souza, R.M.D.: Experimental and numerical analysis of dry contact in the pin on disc test. Wear 301(1), 19-26 (2013)

9. Öqvist, M.: Numerical simulations of mild wear using updated geometry with different step size approaches. Wear 249(1), 6-11 (2001)

10. Ilincic, S., Tungkunagorn, N., Vernes, A., Vorlaufer, G., Fotiu, P., Franek, F.: Finite and boundary element method contact mechanics on rough, artificial hip joints. Proc. Inst. Mech. Eng. Part J: J. Eng. Tribol. 225, 1081-1091 (2011)

11. Ilincic, S., Vernes, A., Vorlaufer, G., Hunger, H., Dörr, N., Franek, F.: Numerical estimation of wear in reciprocating tribological experiments. Proc. Inst. Mech. Eng. Part J: J. Eng. Tribol. 227, 510-519 (2013)

12. Sfantos, G.K., Aliabadi, M.H.: Wear simulation using an incremental sliding boundary element method. Wear 260(9), 1119-1128 (2006)

13. Sfantos, G., Aliabadi, M.: A boundary element formulation for three-dimensional sliding wear simulation. Wear 262, 672-683 (2007)

14. Hegadekatte, V., Hilgert, J., Kraft, O., Huber, N.: Multi time scale simulations for wear prediction in micro-gears. Wear 268(1), 316-324 (2010)

15. Andersson, J., Almqvist, A., Larsson, R.: Numerical simulation of a wear experiment. Wear 271(11), 2947-2952 (2011)

16. Spikes, H.: The history and mechanisms of ZDDP. Tribol. Lett. 17(3), 469-489 (2004)

17. Pereira, G., Lachenwitzer, A., Nicholls, M.A., Kasrai, M., Norton, P.R., De Stasio, G.: Chemical characterization and nanomechanical properties of antiwear films fabricated from ZDDP on a near hypereutectic Al-Si alloy. Tribol. Lett. 18(4), 411-427 (2005)

18. Nicholls, M.A., Norton, P.R., Bancroft, G.M., Kasrai, M.: X-ray absorption spectroscopy of tribofilms produced from zinc dialkyl dithiophosphates on Al-Si alloys. Wear 257(3), 311-328 (2004)

19. Xia, X., Morina, A., Neville, A., Priest, M., Roshan, R., Warrens, C.P., Payne, M.J.: Tribological performance of an Al-Si alloy lubricated in the boundary regime with zinc dialkyldithiophosphate and molybdenum dithiocarbamate additives. Proc. Inst. Mech. Eng. Part J: J. Eng. Tribol. 222(3), 305-314 (2008)

20. Pereira, G., Lachenwitzer, A., Kasrai, M., Norton, P.R., Capehart, T.W., Perry, T.A., ... \& Gilbert, P.U.P.A. A multi-technique characterization of ZDDP antiwear films formed on $\mathrm{Al}(\mathrm{Si})$ alloy (A383) under various conditions. Tribol. Lett. 26(2), 103-117 (2007) 
21. Vengudusamy, B., Green, J.H., Lamb, G.D., Spikes, H.A.: Tribological properties of tribofilms formed from ZDDP in DLC/ DLC and DLC/steel contacts. Tribol. Int. 44(2), 165-174 (2011)

22. Haque, T., Morina, A., Neville, A., Kapadia, R., Arrowsmith, S.: Study of the ZDDP antiwear tribofilm formed on the DLC coating using AFM and XPS techniques. J. ASTM Int. 4(7), 1-7 (2007)

23. de Barros' Bouchet, M.I., Martin, J.M., Le-Mogne, T., Vacher, B.: Boundary lubrication mechanisms of carbon coatings by MoDTC and ZDDP additives. Tribol. Int. 38(3), 257-264 (2005)

24. Vengudusamy, B., Green, J.H., Lamb, G.D., Spikes, H.A.: Influence of hydrogen and tungsten concentration on the tribological properties of DLC/DLC contacts with ZDDP. Wear 298, 109-119 (2013)

25. Vengudusamy, B., Green, J.H., Lamb, G.D., Spikes, H.A.: Durability of ZDDP tribofilms formed in DLC/DLC contacts. Tribol. Lett. 51(3), 469-478 (2013)

26. Kosarieh, S., Morina, A., Lainé, E., Flemming, J., Neville, A.: Tribological performance and tribochemical processes in a DLC/ steel system when lubricated in a fully formulated oil and base oil. Surf. Coat. Technol. 217, 1-12 (2013)

27. Kosarieh, S., Morina, A., Laine, E., Flemming, J., Neville, A.: The effect of MoDTC-type friction modifier on the wear performance of a hydrogenated DLC coating. Wear 302(1), 890-898 (2013)

28. Gosvami, N.N., Bares, J.A., Mangolini, F., Konicek, A.R., Yablon, D.G., Carpick, R.W.: Mechanisms of antiwear tribofilm growth revealed in situ by single-asperity sliding contacts. Science 348(6230), 102-106 (2015)

29. Minfray, C., Martin, J.M., De Barros, M.I., Le Mogne, T., Kersting, R., Hagenhoff, B.: Chemistry of ZDDP tribofilm by ToFSIMS. Tribol. Lett. 17(3), 351-357 (2004)

30. Andersson, J., Larsson, R., Almqvist, A., Grahn, M., Minami, I.: Semi-deterministic chemo-mechanical model of boundary lubrication. Faraday Discuss. 156(1), 343-360 (2012)

31. Bosman, R., Schipper, D.J.: Mild wear prediction of boundarylubricated contacts. Tribol. Lett. 42(2), 169-178 (2011)

32. Bosman, R., Schipper, D.J.: Mild wear maps for boundary lubricated contacts. Wear 280, 54-62 (2012)

33. Hu, Y.Z., Tonder, K.: Simulation of 3-D random rough surface by 2-D digital filter and Fourier analysis. Int. J. Mach. Tools Manuf. 32(1), 83-90 (1992)

34. Tian, X., Bhushan, B.: A numerical three-dimensional model for the contact of rough surfaces by variational principle. J. Tribol. 118(1), 33-42 (1996)

35. Sahlin, F., Larsson, R., Almqvist, A., Lugt, P.M., Marklund, P.: A mixed lubrication model incorporating measured surface topography. Part 1: theory of flow factors. Proc. Inst. Mech. Eng. Part J: J. Eng. Tribol. 224(4), 335-351 (2010)

36. Bulgarevich, S., Boiko, M., Kolesnikov, V., Korets, K.: Population of transition states of triboactivated chemical processes. J. Frict. Wear 31, 288-293 (2010)
37. Bulgarevich, S., Boiko, M., Kolesnikov, V., Feizova, V.: Thermodynamic and kinetic analyses of probable chemical reactions in the tribocontact zone and the effect of heavy pressure on evolution of adsorption processes. J. Frict. Wear 32, 301-309 (2011)

38. Kuzharov, A., Bulgarevich, S., Burlakova, V., Kuzharov, A., Akimova, E.: Molecular mechanisms of self-organization at friction. Part VI. Analysis of thermodynamic features of tribochemical reactions. J. Frict. Wear 28, 218-223 (2007)

39. Fujita, H., Spikes, H.: The formation of zinc dithiophosphate antiwear films. Proc. Inst. Mech. Eng. Part J: J. Eng. Tribol. 218, 265-278 (2004)

40. Fujita, H., Spikes, H.A.: Study of zinc dialkyldithiophosphate antiwear film formation and removal processes, part ii: kinetic model. Tribol. Trans. 48(4), 567-575 (2005)

41. Lin, Y.C., So, H.: Limitations on use of ZDDP as an antiwear additive in boundary lubrication. Tribol. Int. 37(1), 25-33 (2004)

42. Kennedy, F.E.: Frictional heating and contact temperatures. Modern Tribol. Handbook 1, 235-259 (2001)

43. Suárez, A.N.: The Behaviour of Antiwear Additives in Lubricated Rolling-Sliding Contacts. Luleå University of Technology, 2011

44. Zhang, Z., Yamaguchi, E.S., Kasrai, M., Bancroft, G.M.: Tribofilms generated from ZDDP and DDP on steel surfaces: part 1, growth, wear and morphology. Tribol. Lett. 19(3), 211-220 (2005)

45. McQueen, J.S., Gao, H., Black, E.D., Gangopadhyay, A.K., Jensen, R.K.: Friction and wear of tribofilms formed by zinc dialkyl dithiophosphate antiwear additive in low viscosity engine oils. Tribol. Int. 38(3), 289-297 (2005)

46. Nicholls, M.A., Do, T., Norton, P.R., Kasrai, M., Bancroft, G.M.: Review of the lubrication of metallic surfaces by zinc dialkyldithiophosphates. Tribol. Int. 38(1), 15-39 (2005)

47. Spikes, H.A., Cann, P.M.: The development and application of the spacer layer imaging method for measuring lubricant film thickness. Proc. Inst. Mech. Eng. Part J: J. Eng. Tribol. 215(3), 261-277 (2001)

48. Jahanmir, S.: Wear reduction and surface layer formation by a ZDDP additive. J. Tribol. 109(4), 577-586 (1987)

49. Sheasby, J.S., Caughlin, T.A., Mackwood, W.A.: The effect of steel hardness on the performance of antiwear additives. Wear 201(1), 209-216 (1996)

50. Bancroft, G.M., Kasrai, M., Fuller, M., Yin, Z., Fyfe, K., Tan, K.H.: Mechanisms of tribochemical film formation: stability of tribo- and thermally-generated ZDDP films. Tribol. Lett. 3(1), 47-51 (1997)

51. Fuller, M.L.S., Kasrai, M., Bancroft, G.M., Fyfe, K., Tan, K.H.: Solution decomposition of zinc dialkyl dithiophosphate and its effect on antiwear and thermal film formation studied by X-ray absorption spectroscopy. Tribol. Int. 31(10), 627-644 (1998) 